\title{
AGRICULTURE AND RURAL DEVELOPMENT POLICIES AND INSTITUTIONAL FRAMEWORKS; PROPOSED MAPPING FOR WINE TOURISM IN GEORGIA
}

\begin{abstract}
Matsatso TEPNADZE, Ivane Javakhishvili Tbilisi State University, 8 Ilia Tchavtchavadze Avenue, Tbilisi, 0179, Georgia, m.tepnadze@iset.ge

The research paper discusses the growing importance of rural tourism and community based development as a means of sustainable regional development. Growing number of international visitors in Georgia, as well as high agriculture dependence of local population, requires the Government to have a clear long-term strategic vision for tourism and rural development policies. Understanding of the local community role in the sustainable tourism development will enhance the decentralization processes. Experience of developed countries like Italy and German, Czech Republic, New Zealand, etc. shows that in the wake of the emergence of rural tourism, many countries changed and harmonized policies that reflected modification in national regulations and development strategies. The Georgia's favorable climate and soil have historically shaped agriculture one of its most productive economic sectors. Nevertheless, nowadays the sector does not provide favorable economic benefits to the local population. As a promising component, research paper identifies rural tourism as a central stimulator for agriculture sector adding strength to a traditional poor rural economy. Analysis of various existing policy initiatives in Georgia shows urgent need for harmonization of policy documents and local community involvement.
\end{abstract}

Keywords: Decentralization, regional development, rural tourism, sustainable agriculture

\section{INTRODUCTION}

The growing globalization and increased mobility put upward pressure on sustainable and efficient management of local resources. The EU-Georgia Association agreement gives particular importance to local community in the development of sustainable tourism. Growing number of international visitors in Georgia in recent years indicates the need for the appropriate long-term strategic plan for the sector development. Analyzing ongoing decentralization process and policy developments in Georgia, it is obvious that the agriculture sector suffers from a common vision and long -term strategic approach. Existing rural development programs backed with donor financial support, are quite fragmented and lag behind sustainability condition. In spite of the rich natural resources and the growing flow of tourists in Georgia, there is yet, unfavorable living situation for the rural population in the country. Research objective is to study baseline policy framework in Georgia and identify institutional weaknesses. In the end, the study presents empirical data analysis, showing the advantage of targeted region in agro tourism.

\section{RESEARCH METHODS}

The study overviews policy and strategic documents for regional development in Georgia and advanced countries. These include institutional capacity building programs by donor support, as well as independent government policy initiatives for regional development. Keeping in mind Agriculture, as the most favorable sector for Georgia's Economic development, article reviews a few wine tourism development programs in various countries, shows baseline figures in agribusiness in Georgia and uses empirical data and macro-analytical tools for the assessment of the wine tourism potential in Kakheti region.

Polozhentseva, Klevtsova (2015) in their research paper note that expansion of globalization and international competition requires new approaches to social-economic development of the country and its territories. They state that the government should encourage the development of highly specialized regions.

Bruijn, Chitanava (2017) pointed out that Georgia is to a large extent still an agriculture society. Almost half (47.8\%) of the employed working-age population had a job in the agriculture sector. However, fact that agriculture is one of the least productive sector in the country implies that most agriculture workers in Georgian rural regions are stuck in marginal, low productivity employment. Khartishvili et al. (2019) tourism sector with its multifaceted nature is particularly linked with agriculture and is promising for rural development. According to them, rural tourism has become an integral element of rural economies, generating additional employment, income for small communities particularly in remote rural areas. 
Research papers indicate the growing importance of rural tourism and community based development initiatives in sustainable regional development. Yanes et al. (2019) interpret sustainable tourism as a new global standard in terms of self-help, self-reliance and empowerment of communities. This concept is supposed to replace conventional tourism so that many countries designed policies that reflected this shift. Authors interpret a community-based tourism initiative as a collective action of a group of people that belong to a community that decided to develop together a small to medium scale local tourism industry.

Research identified crucial policy problems in the sector development. Khartishvili et al. (2019) pointed out lack of perception of community based tourism in terms of institution, lack of common vision or long-term strategy, and limited innovation for rural tourism development in Georgia. Sidali (2011) states that weaknesses in farm tourism in Italy lead to a delayed development in strategic organizational planning. Similarly, Hinteregger (2014) states that lack of tourism products and additional tourism attractions are attributable for the South Kosovo region. Musso (2015) emphasizes the lack of strategy in Italian Wine cluster regions and states that initiatives have been conducted in unplanned manner and without a clear objective. Authors conducted analysis of three wine tourism attraction places in Italy and found out that increased tourism flows towards destinations lead wine local producers to adopt by strengthening cooperation with those involved in tourist activities. Stakeholder involvement and development of task force is important institutional pillar for the community based tourism development in regional municipalities. According to Hinteregger (2014) the key players comprise line ministries, local municipalities, donor organizations, local population, owners of accommodation facilities, restaurants, cafes, etc. Author in proposes a task force development as the highest priority activity in the wine tourism development plan. Khartishvili et al. (2019) points the USAID "Growth" project, which advocated the cooperation of regional public and private sectors. Yanes et al. (2019) note that high level of participation of communities is what separates CBT from participation in conventional tourism. Tourism initiated and led by the communities is more likely to maximize the desired social and economic outcomes.

Literature review referred a wine tourism and its contribution to local communities. Johnson et al. (2000) note that wine tourism are important components in the wine industry and the tourism industry. Hall (2000) describe Wine Tourism as tourist activities with visits to vineyards, wineries, wine festival, wine testing and introducing type of local wine to motivate tourists to come to a destination. Hinteregger (2014) in its wine tourism development plan for South Kosovo proposed a tourism destination concept as a combination of several different and independent elements such as Tourism Suprastructure, and tourism infrastructure, Natural resources and historic sights, Entertainment and infotainment, events and transportation. He states that wine, Grapes, Active and Nature should be the four main pillars of positioning of the targeted region. Surprisingly this approach combines various local resources, so that it creates incentives to adjust the country strategic plan for decentralization according to the regional specialization.

Georgian authors, namely: Gagnidze (2015; 2016; 2018), Gogorishvili (2016), Lekashvili (2017), PaPachashvili and Tsimakuridze (2010), Sepashvili (2015; 2016a; 2016b), emphasize about the necessity of reforms for regional cluster policy developments in the economy of Georgia.

The different policy frameworks that are currently in place and which take into account the development of the country regions are as follows:

- A 10 -year plan of the National Tourism Development Strategy of Georgia. While the strategy refers to visitor experiences, there are no mapping alternative forms of tourism, such as eco, agro or rural tourism;

- The Rural Development Strategy of Georgia 2017-2020 ENPARD is intended to tackle rural poverty in Georgia. However, the strategic plan is somewhat fragmented does not have a strategic linkage with rural tourism development in Georgian regions. It should be noted that the strategy lacks of monitoring and evaluation of annual completions reports and performance indicators.

- In 2018, the Parliament and Government of Georgia presented a new national vision of decentralization and local self-governance, which is supposed to increase decision-making powers and financial resources of the regional and local authorities, empowering them to better address the needs of local communities. In 2019 the National Government approved the strategic document. Using a top-down approach, the strategy formulated stimulating outlook but lacks of relevant policy analysis as a necessary precondition for the enhancement of full and effective decentralization process. The proposed projections made over a medium term for the next 5 years looks like a general wish list missing objective judgment and baseline analysis.

- A Mountain Law and a Mountain Development Strategy promote mountain tourism as a sustainable development option. However, the strategy approved without regulatory impact assessment.

\section{RESEARCH RESULTS}

Evidence suggests that current regional development policies in Georgia are quite fragmented and suffer from a long term harmonized strategic vision. There is essential need to rethink and create viable conditions for rural development in Georgia. The EU-Georgia Association agreement place emphasis on cooperation in agriculture and rural development through progressive convergence of policies and sustainability mechanisms. Current favorable conditions in Georgian agriculture sector necessitates to promote quality policies and administrative capacities at central and local level needed to plan, evaluate, implement and enforce policies in accordance with best practices. 
Despite the clearly demonstrated agriculture nature of Georgia regions, the most poverty related indicators suggest that majority of active population in rural areas are in an economically disadvantaged positions. Case study of Kakheti region unfolds the rural development problems. Data analysis show that approximately $77 \%$ of rural population actively engaged in agriculture sector ${ }^{1}$. The poverty related indicators such as working in agriculture and being a self-employed, apply to the absolute majority of rural population in the region.

It is obvious that the agriculture sector in Georgia ineffectively meets the both the global patterns and the local residents' economic needs. Rural people overwhelmingly employ in marginal, low productivity agriculture jobs. The graph bellow illustrates that the share of agribusiness in total Economy output is very low and has been steadily declining for the last 4 years.

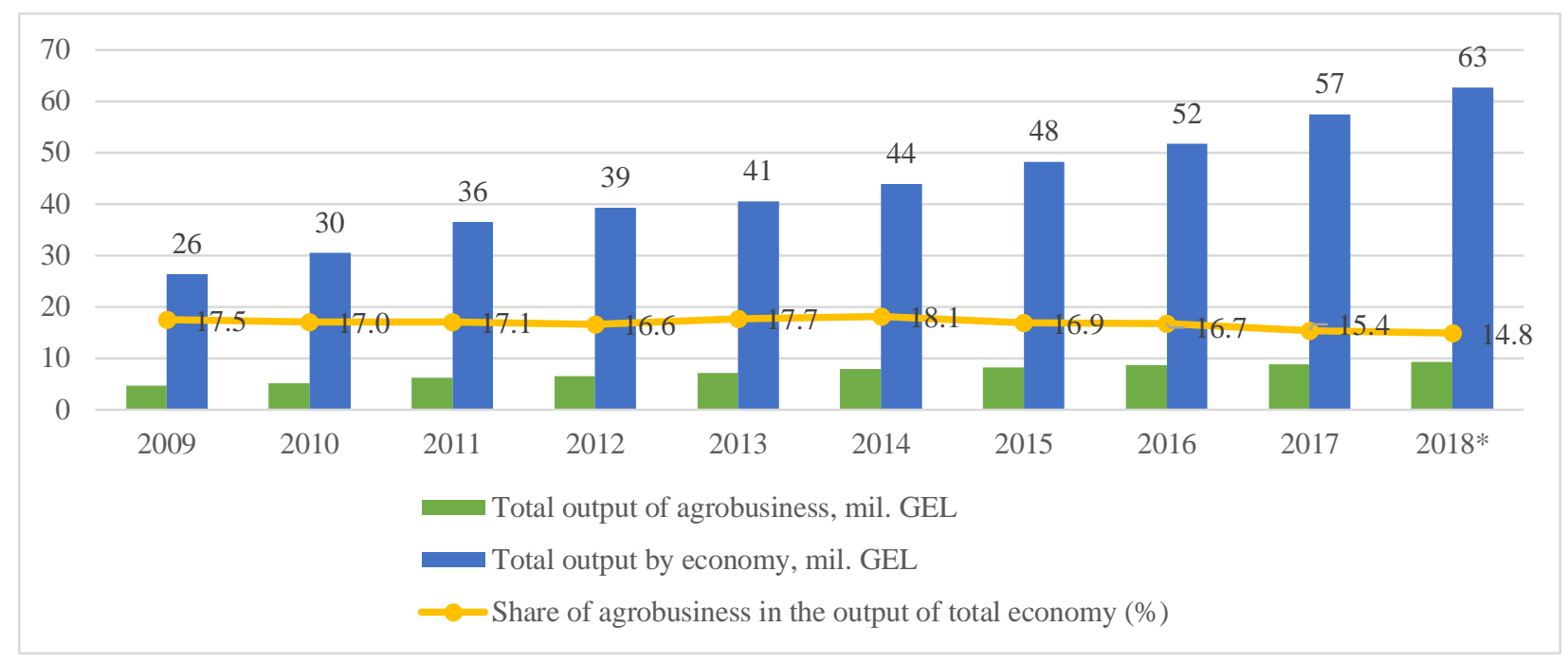

Figure 1. Share of agribusiness in the output of total Economy (\%)

Based on the results of the calculation of the coefficients for the determination of the potential for establishing a agro tourism cluster, we used macro analytical tools suggested by porter; these are:

1. Localizationn quotient (LQ) $=\frac{\frac{x}{X}}{\frac{y}{Y}}$

Where: $\mathrm{x}$ - number of employees working in the wine sector in a region; $\mathrm{X}$ - Total number of employees in the region; $\mathrm{y}-\mathrm{the}$ number of employees working in the wine sector in the country; $\mathrm{Y}$ - number of employees in the country.

2. Concentration quotient $(\mathrm{CQ})=\frac{\frac{a}{A}}{\frac{b}{B}}$

Where: $\mathrm{a}$ - the number of vineyards in a region certified by the association rules (ha); A- total number of vineyards across the region (ha); b- the number of vineyards of all the association in the country (ha); B - total area of vineyards in the country (ha).

The localization and concentration quotients calculated for the 9 sub-regions and one autonomous republic in Georgia shows that Kakheti region has the highest coefficients. Due to the relatively high regional employment in wine production sector, the region has a clear competitive advantage to develop sustainable wine tourism cluster (Fig. 2 and 3). It should be noted that the wine sector has a clear support from the endogenous population in Kakheti region. Policies oriented toward local population should be based on local priority needs and therefore policy development process should take a bottom up approach.

Harmonized state and regional policies will be effective with local community involvement. High participation of local community includes not only participation in planning and management, but also comprise influencing decisions and outcomes. Community based initiatives effectively enhance decentralization process and achieve sustainable rural development in Georgia.

\footnotetext{
${ }^{1}$ Geostat, Regional statistics, 2019 www.Geostat.ge
} 


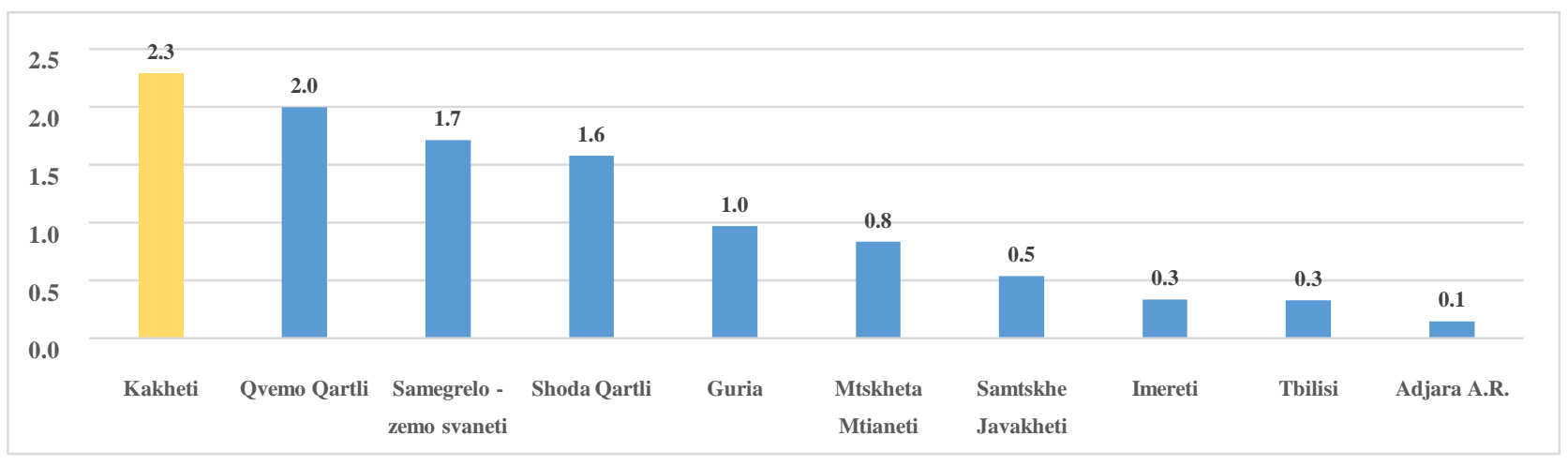

Figure 2. Localization Quotients for local regions in Georgia, 2018

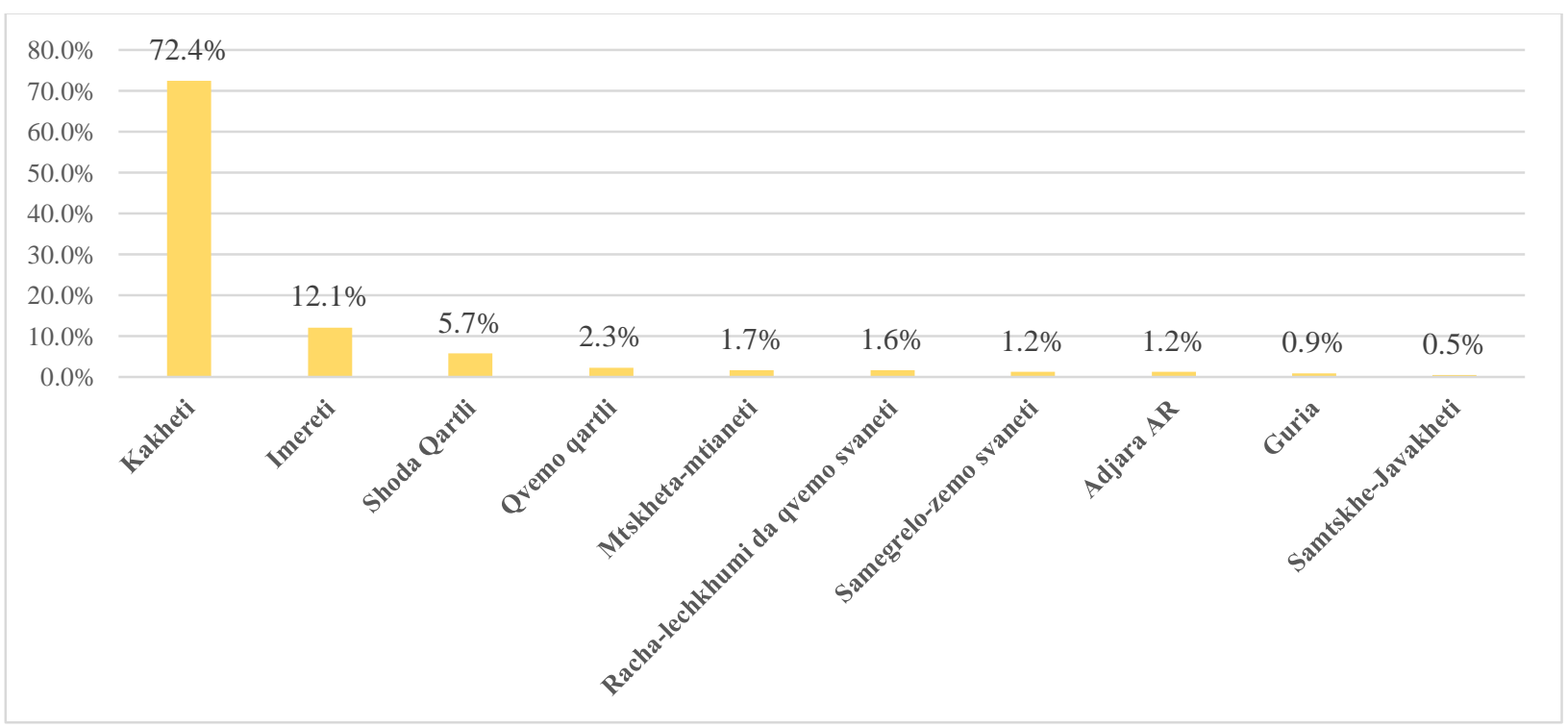

Figure 3. Concentration quotients in Wine production of Georgia by sub regions, 2018

\section{CONCLUSIONS AND DISCUSSIONS}

Upward pressure of competition required deeply specialized regions in Georgia. Rural tourism in Georgia necessitate long-term strategic outlook which can be achieved by extensive policy analysis across adjacent sectors. Community based initiatives require understanding of high participatory principles in tourism sector. The recent policy development in Georgia reveals that tourism is among top priorities of the government of Georgia. However, existing strategic programs and policies suffer from fragmentation and require to be created under the umbrella of sustainability. The community based tourism will enable sustainable rural tourism and enhance decentralization process in the country. The stakeholder involvement and the development of strong task force is an important institutional pillar for the community empowerment in regional municipalities in Georgia. Assessment of localization and concentration quotient for the vineyards across the nine regions of Georgia, it can be concluded that Kakheti has a clear competitive advantage in wine tourism development.

\section{REFERENCES}

1. Arcana K., 2017. Development of Wine Tourism and Its Impact for Local Community in North Bali, Advances in Economics, Business and Management Research, $1^{\text {st }}$ International Conference on Tourism Gastronomy and Tourism Destination,

2. Bruijn D. B., Chitanava M., 2017. Aging and Older Persons, an Overview based on the 2014 General Population Census Data, National Statistics Office of Georgia, and United Nations Population Fund (UNPFA) Office in Georgia

3. Gagnidze I. 2018. The Role of International Educational and Science Programs for Sustainable Development (Systemic Approach). Kybernetes, Vol. 47, No. 2, pp. 409-424. https://doi.org/10.1108/K-03-2017-0114 (Accessed 16 February, 2018).

4. Gagnidze I. 2016 Entrepreneurial university: Subsystem determining the success of clusters”, Book of Abstracts, Business Systems Laboratory 4th International Symposium, 'Governing Business Systems. Theories and Challenges for Systems. Thinking in Practice', Vilnius, Lithuania, pp. 179-182. http://bslab-symposium.net/Vilnius.2016/BSLab-Vilnius2016-ebook of Abstracts.pdf (Accessed 14 February 2018).

5. Gagnidze I. 2015. Cluster as a tool for the challenges of development. Strategica International Academic Conference, Third Edition 'Local versus Global', Bucharest, Romania, October 29-31, pp. 336-344. http://strategica- 
conference.ro/wpcontent/uploads/2016/01/Strategica-2015-Challenges-of-Integration-into-theWorld-Economy.pdf (Accessed 14 February 2018).

6. Gogorishvili I. 2016. Foreign economic policy of Georgia since gaining the Independence'. Estonian Discussions on Economic Policy, Topical issues in the EU Member States. 1/2016, Berlin-Tallin. pp. 33-47. http://www.mattimar.ee/publikatsioonid/majanduspoliitika/2016/1_2016_krooni ka.pdf (Accessed 10 February, 2018).

7. Hall C.M., Longo A.M., Mitchell R., Johnson G. 2000. Wine tourism in New Zealand. Oxford, Elsevier Science.

8. Hinteregger C., "Wine Routes and the Development of Wine Culture in the South of Kosovo, Wine Tourism Development Plan, South Kosovo

9. Gary J., Cambourne B., Mitchell R. 2000. Wine Tourism around the World: Development, Managementa nf Markets. Oxford: Elsevier Science.

10. Kharatishvili L., Muhar A., Dax T., Khelashvili I., 2019. Rural Tourism in Georgia in Transition: Challenges for Regional Sustainability. Tourism Hospitality Management Department, Faculty of Economics and Business Ivane Javakhishvili Tbilisi State University, https://doi.org/10.3390/su11020410

11. Lekashvili E. 2017. International Assessments Analyses of Systemic Transformation of Georgia's Economy, Global Journal of Management and Business Research. Economics \& Commerce, DIO: 10.17406/GJMBR, Volume 17 ISSUE 5 (VER 1.0), Open Association of Research $\quad$ Society, $\quad$ pp. https://globaljournals.org/GJMBR_Volume17/EJournal_GJMBR_(B)_Vol_17_Issue_5.pdf (Accessed 9 February, 2018).

12. Musso F., Francioni B., 2015. Agri-food Cluesters, Wine Tourism and Foreign Markets. The Role of Local Networks for SME's Internalization. "Department of Economics, Society and Politics, Carlo Bo University, Urbino, Italy, https://doi.org/10.1016/S2212-5671(15)01004-7

13. Papachashvili N., Tsimakuridze T. 2010. Georgia's education system cluster development conception related issue. Collection of materials of international scientific-practical conference 'Actual Economic Problems at Current Stage of Global Development', pp. 593-605 (in Georgian). http://www.pgie.tsu.ge/contentimage/konferenciebi/2010_Konferencia.pdf (Accessed 12 February, 2018).

14. Polozhentseva Y., Klevtsova M., 2015. Instruments of Development of Cluster Policy:Stages, Models, International Practice. 22 $2^{\text {nd }}$ International Economic Conference - IECS 2015 "Economic Prospects in the Context of Growing Global and Regional Interdependencies", https://doi.org/10.1016/S2212-5671(15)01029-1

15. Prokes M., Skalova E., Nemcik L. 2017. Wine Cluster Key Driver of Success for Wine Tourism in the Czech Republic, The International Scientific Conference INPROFORUM, Mendel University in Brno, Czech Republic

16. Sepashvili E. 2016a. Globalized World Economy, Innovations and National Policies for Economic Growth. Business Systems Laboratory 4th International Symposium, 'Governing Business Systems. Theories and Challenges for Systems. Thinking in Practice’, ISBN: 9788890824234, Vilnius, Lithuania, pp. 174-76.

17. Sepashvili E., Gazzola P., Pezzetti R. 2016b. Corporate Social Responsibility as a Mean To Promote Gender Equality. 11th International Silk Road Conference on Innovations in Business, Education and Science, pp. 77-83, Tbilisi, Georgia, May 20-21. http://silkroadinstitute.ibsu.edu.ge/Uploads/Books/SILK.pdf (Accessed 10 February, 2018).

18. Sepashvili E. 2015. Integration with the EU: Prospects for Foreign Trade of Eastern Partnership Countries, Strategica International Academic Conference, Third Edition 'Local versus Global', Bucharest, Romania, October 29-31, 2015, pp. 362-371

19. Sidali K., 2011. A Sideways Look at Farm Tourism in Germany and in Italy. Research article, Georg-August University of Gottingen, Department of Agriculture Economics and Rural Development https://doi.org/10.1007/978-3-642-11361-1_1

20. Theus F., Zeng D., 2010 Agriculture Clusters. Thematic Note, World Bank Institute, World Bank.

21. Yanes A., Zielinski S., Cano M., Kim S., 2019 Community-Based Tourism in Developing Countries: A framework for Policy Evaluation. Research Institute of Agriculture and Life Sciences, Seoul National University, https://doi.org/10.3390/su11092506

22. ENPARD - Rural Development Strategy Georgia (2017-2020) 10 -year plan of the National Tourism Development Strategy of Georgia

23. The 2019-2023 Strategy for the Development of Georgia's Mountain Settlements The Decentralization strategy of Georgia. 